\title{
n-3 Fatty acids, hypertension and risk of cognitive decline among older adults in the Atherosclerosis Risk in Communities (ARIC) study
}

\author{
May A Beydoun 1,*, Jay S Kaufman ${ }^{2,3}$, Philip D Sloane ${ }^{4}$, Gerardo Heiss ${ }^{2}$ and \\ Joseph Ibrahim $^{5}$ \\ ${ }^{1}$ Center for Human Nutrition, Department of International Health, Johns Hopkins Bloomberg School of Public \\ Health, 615 N Wolfe Street E2610, Baltimore, MD 21205, USA: ${ }^{2}$ Department of Epidemiology, School of \\ Public Health, University of North Carolina at Chapel Hill, Chapel Hill, NC, USA: ${ }^{3}$ Carolina Population Center, \\ University of North Carolina at Chapel Hill, Chapel Hill, NC, USA: ${ }^{4}$ Department of Family Medicine, School of \\ Medicine, University of North Carolina at Chapel Hill, Chapel Hill, NC, USA: ${ }^{5}$ Department of Biostatistics, \\ School of Public Health, University of North Carolina at Chapel Hill, Chapel Hill, NC, USA
}

Submitted 4 August 2006: Accepted 5 February 2007: First published online 12 July 2007

\begin{abstract}
Objective: Recent research indicates that $n-3$ fatty acids can inhibit cognitive decline, perhaps differentially by hypertensive status.

Design: We tested these hypotheses in a prospective cohort study (the Atherosclerosis Risk in Communities). Dietary assessment using a food-frequency questionnaire and plasma fatty acid exposure by gas chromatography were completed in 1987-1989 (visit 1), while cognitive assessment with three screening tools - the Delayed Word Recall Test, the Digit Symbol Substitution Test of the Wechsler Adult Intelligence Scale-Revised and the Word Fluency Test (WFT) was completed in 1990-1992 (visit 2) and 1996-1998 (visit 4). Regression calibration and simulation extrapolation were used to control for measurement error in dietary exposures.

Setting: Four US communities - Forsyth County (North Carolina), Jackson (Mississippi), suburbs of Minneapolis (Minnesota) and Washington County (Maryland).

Subjects: Men and women aged 50-65 years at visit 1 with complete dietary data $(n=7814)$; white men and women in same age group in the Minnesota field centre with complete plasma fatty acid data $(n=2251)$.

Results: Findings indicated that an increase of one standard deviation in dietary long-chain $n-3$ fatty acids (\% of energy intake) and balancing long-chain $n-3$ / $n-6$ decreased the risk of 6-year cognitive decline in verbal fluency with an odds ratio ( $95 \%$ confidence interval) of $0.79(0.66-0.95)$ and $0.81(0.68-0.96)$, respectively, among hypertensives. An interaction with hypertensive status was found for dietary long-chain $n-3$ fatty acids $\left(\mathrm{g} \mathrm{day}^{-1}\right.$ ) and WFT decline (likelihood ratio test, $P=0.06$ ). This exposure in plasma cholesteryl esters was also protective against WFT decline, particularly among hypertensives $(\mathrm{OR}=0.51, P<0.05)$. Conclusion: One implication from our study is that diets rich in fatty acids of marine origin should be considered for middle-aged hypertensive subjects. To this end, randomised clinical trials are needed.
\end{abstract}

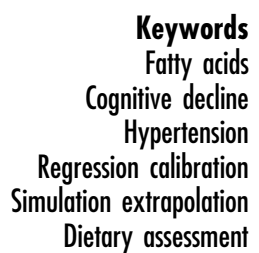

On the basis of recent United Nations estimates, the proportion of the US population aged 65 years and over was $12.3 \%$ in 2000 and is projected to increase rapidly in the coming decades to reach $20 \%$ by $2050^{1}$. As populations age, all cognitive disorders, including dementia, become more common. Recent research indicates that $n-3$ fatty acids may be important in preventing cognitive decline. So far, epidemiological evidence, although inconclusive, suggests a protective effect of $n-3$ fatty acid intake in the $\operatorname{diet}^{2-4}$. Essential fatty acids are linked to several biochemical and biophysical functions, including structural integrity and fluidity of membranes, enzyme activities, lipid-protein interactions and serving as precursors for eicosanoids such as prostaglandins, 
leukotrienes and thromboxanes ${ }^{5}$. The fatty acid composition of neuronal cell-membrane phospholipids reflects the intake of fatty acids in the $\operatorname{diet}^{6}$ and fish oils, which contain high levels of C20 and C22 polyunsaturated fatty acids (PUFAs), exert the most profound influence on brain PUFA concentration. According to experimental animal studies, there is a plausible pathway by which hypertension and low dietary $n-3$ fatty acid intake may interact in increasing the risk of cognitive decline. In fact, hypertensive rats tended to have lower brain concentrations of monounsaturated fatty acids and PUFAs than normotensive rats ${ }^{7}$, possibly due to pressure-induced endothelial dysfunction at the blood-brain barrier or exhausted astrocytic metabolism. Oxidative stress which accompanies high blood pressure leads to increased peroxidation of unsaturated fatty acids and a reduction in their concentration in the brain represents an alternative explanation.

Despite animal experimental evidence for a possible biological interaction between dietary intake of $n-3$ fatty acids and hypertensive status ${ }^{7-10}$ in affecting cognitive decline, no epidemiological study has attempted to test this hypothesis to date. The present observational prospective study assessed the effect of low $n-3$ fatty acid status on 6-year cognitive decline in men and women aged 50 years and older. A secondary objective was to explore whether hypertensive subjects would benefit to a larger extent than normotensive subjects from this increased intake.

\section{Data and methods}

\section{Study sample}

The Atherosclerosis Risk in Communities (ARIC) study is an ongoing prospective cohort study aimed at investigating the aetiology of atherosclerosis and its clinical sequelae, and the longitudinal impact of variation in cardiovascular risk factors, medical care and disease, by race, sex, place and time. In each of four US communities - Forsyth County (North Carolina), Jackson (Mississippi), suburbs of Minneapolis (Minnesota) and Washington County (Maryland) - 4000 adults aged 45-64 years were examined four times, 3 years apart (visits 1 to 4). Three out of the four cohorts represented the ethnic mix of their communities, while at Jackson (Mississippi) only African American residents were recruited ${ }^{11}$. Out of the total sample examined at baseline $(N=15792)$ we restricted these analyses to 11557 individuals aged 50 years or older at baseline since research clearly shows that risk of cognitive decline in general, and of dementia in particular, is negligible prior to the age of 60 years (which is the age at which the youngest individuals in this cohort were reexamined at visit 4$)^{12}$. Eligibility for these analyses further required survival to visit $4(n=8346)$, complete data on cognitive functioning at visits 2 (1990-1992) and
4 (1996-1998) ( $n=8012)$ and complete dietary intake at visit 1 (1987-1989), which yielded 7814 men and women. Of these, plasma fatty acid data at visit 1 were available for a subset of the Minneapolis (Minnesota) cohort $(n=2251)$.

\section{Outcome assessment}

Three measures of cognitive functioning were made only at visits 2 and 4 among the total ARIC cohort, and these measures relied on the following instruments: the Delayed Word Recall Test (DWRT) ${ }^{13}$, the Digit Symbol Substitution Test of the Wechsler Adult Intelligence Scale-Revised (DSST/WAIS-R) ${ }^{14}$, and the Word Fluency Test (WFT) of the Multilingual Aphasia Examination, also known as the controlled oral word association ${ }^{15}$.

DWRT. This screening tool assesses verbal learning and recent memory. It requires the respondent to recall 10 common words after a 5-min interval during which another test is administered. Test scores may range between 0 and 10 words recalled and the time limit for recall is set at $60 \mathrm{~s}$. The 6-month test-retest reliability of DWRT was previously shown to be high among 26 normal elderly individuals (Pearson correlation coefficient, $r=0.75)^{13}$.

DSST/WAIS-R. This test is a paper-and-pencil test requiring timed translation of numbers $1-9$ to symbols using a key. The test measures psychomotor performance and is relatively unaffected by intellectual ability, memory or learning for most adults ${ }^{15}$. It appears to be a sensitive and reliable marker of brain damage ${ }^{16}$. The test score can range between 0 and 93 and reflects the correctly translated number of digit-symbol pairs within a time limit of $90 \mathrm{~s}$. Short-term test-retest reliability over $2-5$ weeks has been found to be high in individuals aged 45-54 years $(r=0.82)^{14}$.

WFT. This test requires subjects to record as many words as possible using the initial letters F, A and S, and to list these words, the subject is given only $60 \mathrm{~s}$ per letter. The total score corresponds to the total number of words generated during these three trials. The test is particularly sensitive to linguistic impairment ${ }^{15,17}$ and early mental decline in older persons ${ }^{18}$. It is also a sensitive marker of damage in the left lateral frontal lobe ${ }^{15,17}$. The immediate test-retest correlation coefficient based on an alternative test form has been found to be high $(r=0.82)^{19}$.

Preliminary analysis suggested that while visits 2 and 4 scores of DSST/WAIS-R and WFT had a correlation coefficient close to 0.5 , the correlation between DSST/WAIS-R and DWRT was 0.4 and that between DWRT and WFT was about 0.4. However cognitive changes (visit 4-visit 2) in each of these scales had much weaker correlations with each other, ranging between 0.06 and 0.09 .

Cut-off points were determined for decline in each of the three cognitive status tests using the Reliable Change Index (RCI) method, in order to correct for measurement 
error and practice effects ${ }^{20}$. RCI is defined as $\left[\left(X_{2}-X_{1}\right)-\left(M_{2}-M_{1}\right)\right] /$ SED, where $X_{1}$ is the individual's score at baseline, $X_{2}$ the individual's score at follow-up, $M_{1}$ and $M_{2}$ are the group mean pre-test and follow-up scores, respectively, and SED is the observed standard error of the difference scores. Scoring below an RCI of -1.645 was regarded as a 'statistically reliable' deterioration in the test scores.

A composite measure of the three RCIs to assess global cognitive decline was created using principal components analysis, a data-reduction technique ${ }^{21}$. Similarly, the cut-off point of the composite score for statistically reliable global cognitive decline was chosen to be -1.645 .

\section{Exposure assessment}

Usual dietary intake was estimated from an intervieweradministered 61-item semi-quantitative food-frequency questionnaire (FFQ) previously developed and validated by Willett et al. against multiple food records among a sub-sample of the Nurses' Health Study cohort ${ }^{22}$. Dietary intake of essential fatty acids and their elongated and desaturated products was expressed as a \% of total energy intake and grouped under four main categories, as suggested by Lands et $a l^{23,24}$.

1. C18 n-3 PUFAs, $18: 3+18: 4 n-3$ (3P);

2. C18 n-6 PUFAs, $18: 2+18: 3 n-6$ (6P);

3. $\mathrm{C} 20$ and $\mathrm{C} 22$ n-3 highly unsaturated fatty acids (HUFAs): $20: 5+22: 5+22: 6 n-3(3 \mathrm{H})$; and

4. $\mathrm{C} 20$ and C22 n-6 HUFAs: $20: 3+20: 4+22: 4+$ $22: 5 n-6(6 \mathrm{H})$.

Sums of fatty acid intake as \% of energy included $3=3 \mathrm{P}+3 \mathrm{H}$ and $6=6 \mathrm{P}+6 \mathrm{H}$. Ratios of interest included $3 \mathrm{P} / 6 \mathrm{P}, 3 \mathrm{H} / 6 \mathrm{H}$ and $(3 \mathrm{P}+3 \mathrm{H}) /(6 \mathrm{P}+6 \mathrm{H})$, also denoted $3 / 6$. In multivariate models, all these variables were standardised by subtracting each observation from the variable mean and dividing the difference by the standard deviation (SD). Hence, the main exposures of interest were 3P, $3 \mathrm{H}, 3$ (as \% of energy intake), $3 \mathrm{P} / 6 \mathrm{P}, 3 \mathrm{H} / 6 \mathrm{H}, 3 / 6$ and total $3 \mathrm{H}$ (in $\mathrm{g} \mathrm{day}^{-1}$ ). Adjustment was made for the other fatty acid variables, and total energy intake was considered as a potential confounder to emulate a multivariate nutrient density model $^{25}$.

Twelve-hour fasting blood was collected according to the ARIC study-wide protocol. The Minneapolis field centre conducted fatty acid analysis of plasma phospholipid and cholesteryl ester fractions on visit 1 blood specimens. The procedure is described in detail elsewhere ${ }^{26}$. The identity of 28 fatty acid peaks was revealed by gas chromatography by comparing each peak's retention time with the retention times of fatty acids in synthetic standards of known composition. The relative amount of each fatty acid (as \% of all fatty acids) was calculated by integrating the area under the peak, dividing the result by the total area for all fatty acids, and multiplying by 100. Data from the chromatogram were transferred electronically to a computer for analysis. Plasma exposures are expressed as $\%$ of total fatty acids in each fraction and were grouped similarly to dietary exposure. Test-retest reliability coefficients (individuals sampled three times, 2 weeks apart) for various plasma fatty acids ranged from $0.50-0.93$ for cholesteryl esters to 0.89 for phospholipids ${ }^{27}$. However, only $3 \mathrm{H}$ and the ratio $3 \mathrm{H} / 6 \mathrm{H}$ were considered in these analyses.

\section{Replicate dietary measures}

Dietary intake was assessed among the surviving ARIC sample at visit 3 (1992-1994), using the same semiquantitative FFQ that was administered at baseline. At visit 2, a sub-sample of ARIC (around 10\% of the original sample) was asked to repeat the FFQ. As stated earlier, of our eligible subset with baseline data on exposure and complete outcome data $(n=7814), 657$ had data on visit 2 exposure, 7482 had complete data at visit 3, while 634 had both.

\section{Covariates}

Most covariates considered as potential confounders were measured at visit 1, although some were defined according to criteria that spanned all four visits. Covariates can be subdivided into sociodemographic, genetic, health behaviours and nutritional. Age, gender, ethnicity and education were all reported by the respondent. Apolipoprotein E (ApoE) genotype was categorised as 0 to indicate the absence of an $\varepsilon 4$ allele vs. 1 to denote carrier status for at least one $\varepsilon 4$ allele. Among the behavioural factors (all measured at visit 1), smoking was represented on a three-level categorical scale, i.e. never smoked, smoked previously and current smoker. FFQ-derived values of alcohol $\left(\mathrm{g} \mathrm{day}^{-1}\right)$ and caffeine $\left(\mathrm{mg} \mathrm{day}^{-1}\right)$ were considered as well. Physical activity was assessed using a questionnaire developed by Baecke et al. that included 16 items about usual exertion ${ }^{28}$. A validated index of physical activity was derived at visit 1 , summing sports, work and leisure indices which ranged from a score of 1 (low) to 5 (high) ${ }^{29}$. Body mass index at visit 1 was computed by dividing weight $(\mathrm{kg})$ by the square of height $\left(\mathrm{m}^{2}\right)$. Baseline dietary intake of antioxidants and other micronutrients (mainly vitamins $\mathrm{B}_{6}$, $\mathrm{B}_{12}$ and folate) was also considered ${ }^{22}$. The association of these covariates with our outcome has been documented previously by similar cohort studies based on ARIC data $^{30-33}$.

Our main effect modifier, hypertension, was operationalised using measured systolic and diastolic blood pressure at each visit as well as use of antihypertensive medication over the past two weeks. Seated blood pressure levels were calculated as the average of the second and third of three consecutive measurements with a random-zero sphygmomanometer. Hypertension was defined as systolic blood pressure $\geq 140 \mathrm{mmHg}$ and diastolic blood pressure $\geq 90 \mathrm{mmHg}$ or the use of 
antihypertensive medication during the two weeks prior to examination on any of visits 1 to 4 .

\section{Statistical analysis}

We carried out univariate analyses of predictor and outcome variables as well as covariates. For bivariate analyses of exposure and outcome, we computed means of predictor variables across outcome groups $(0=$ no decline; $1=$ decline) and assessed the statistical significance of differences using the independent-samples $t$-test at an $\alpha$ level of 0.05 . We computed odds ratios of decline with increase in each exposure by 1 SD through a multivariate logistic regression analysis. Control for confounding was accomplished using backward elimination and an overall change in estimate criterion of 5\%. Covariates which changed the estimated effect of the exposure by more than $5 \%$ were retained in the final model ${ }^{34}$.

Hypertension was considered as a potential effect modifier. Likelihood ratio tests were used to assess statistical significance of the interaction between exposure and hypertensive status at a type I error level of 0.20 , after obtaining the final parsimonious model ${ }^{35,36}$. The multivariate models can be summarised by equations (1) and (2):

$\operatorname{Logit}[\operatorname{Pr}(Y=1 \mid Q, Z)]=\beta_{0}+\beta_{1} Q_{1}+\sum \beta_{2 i} Q_{2 i}+\sum \beta_{j} Z_{j}$

$$
\begin{aligned}
\operatorname{Logit}[\operatorname{Pr}(Y=1 \mid Q, Z, H)]= & \beta_{0}+\beta_{1} Q_{1}+\sum \beta_{2 i} Q_{2 i}+\beta_{3} H \\
& +\sum \beta_{j} Z_{j}+\gamma Q_{1} \times H
\end{aligned}
$$

In the above equations, $Q_{1}$ is the main exposure of interest as derived from the FFQ, $Q_{2 i}$ are the other fatty acids that might act as confounders, $Z_{j}$ is a vector of potential confounders that are assumed to be perfectly measured (i.e. no error variance associated with them) and $H$ is the potential effect modifier 'hypertensive status', also assumed to be perfectly measured. The same process was used with the plasma exposures in cholesteryl esters and phospholipids. To correct for measurement error in dietary exposure, a sensitivity analysis was conducted for models (1) and (2) whereby regression calibration (RCAL) and simulation extrapolation (SIMEX) were applied to the final parsimonious models for each outcome/exposure pair $^{37,38}$. In a multivariate setting, both RCAL and SIMEX rely on the method of moments and attempt to estimate the error variance in the error-prone exposure and adjust the exposure-outcome effect using different procedures. In both cases, replicate measures of FFQ measurements at visits 2 and 3 were used for the correction. The two methods are described in more detail in Appendix A. Statistical analyses were conducted using STATA version $9.0^{39}$.

\section{Results}

\section{Characteristics of study subjects}

Table 1 shows the characteristics of study subjects according to availability of dietary and plasma fatty acid data as well as cognitive assessment data at both points in time. Subjects in the plasma fatty acid group ('plasma group' hereafter) consisted of whites residing in the suburbs of Minneapolis. They were in general more educated than the dietary group, which was a mix from all ARIC centres. They had a lower proportion of women (50.7\% vs. 54.6\%), a lower prevalence of the ApoE $\varepsilon 4$ allele (28.8\% vs. 30.0\%), a higher proportion of 'ever smoked' status (59.6\% vs. 55.5\%), and greater consumption of alcohol and caffeine. Some differences were noted for other behavioural and nutritional factors as well. Hypertensive status was particularly high in the dietary group (56.0\%) compared with the plasma group (49.3\%). Raw mean scores of baseline cognitive function were greater among those in the plasma than in the dietary group and average declines between visits 2 and 4 were found to be steeper in the former. Table 2 summarises the distribution of dietary and plasma fatty acid exposures considered. The SDs for $\mathrm{Q}_{1}, \mathrm{M}$ and $\mathrm{N}$ are of particular importance in interpreting multivariate logistic regression analysis. $Q_{2}$ and $Q_{3}$ represent replicate measurements on $\mathrm{Q}_{1}$ at visits 2 and 3 which were used to correct for measurement error in the exposure.

\section{Multivariate analysis findings: dietary exposures}

Multivariate logistic regression models of the relationship between dietary exposure and cognitive decline are presented in Table 3. Results indicate that risk of clinically significant decline in DWRT over the period of 6 years was reduced modestly with every $1 \mathrm{SD}$ increase in longchain $n-3$ fatty acid intake $(3 \mathrm{H})$ as \% of total energy intake. This was observed in the total population and among the hypertensive subgroup. For DSST/WAIS-R, although the ratio $3 \mathrm{H} / 6 \mathrm{H}$ was protective against decline, this effect did not reach statistical significance. However, the likelihood ratio test indicated a significant level of interaction between this exposure and hypertensive status, shown by the variation in effect across strata of the effect modifier (1.09 among normotensives vs. 0.88 among hypertensives). Risk of decline in WFT was reduced by long-chain and all types of $n-3$ fatty acid intake ( $3 \mathrm{H}$ and 3$)$ as $\%$ of total energy intake, by the ratio $3 \mathrm{H} / 6 \mathrm{H}$ and by $3 \mathrm{H}$ in $\mathrm{g} \mathrm{day}^{-1}$. This relationship was stronger among hypertensive subjects and a significant interaction was noted for $3 \mathrm{H}$ in $\mathrm{g} \mathrm{day}^{-1}$ (likelihood ratio test, $P=0.06)$. No statistically significant results were observed for global cognitive decline or other dietary exposures. After adjusting for measurement error in the dietary covariate using RCAL, loss of precision in measures of effect was observed. In most cases, bias seemed to be towards the null when comparing naive and 
Table 1 Characteristics of study subjects with complete cognitive and dietary data between visits 1 and 4 (dietary group; $N=7814$ ) and those with complete cognitive and plasma data (plasma group; $N=2251$ ); ARIC, 1987-1998

\begin{tabular}{|c|c|c|}
\hline Characteristic & Dietary group (all ARIC centres) & Plasma group (MN whites) \\
\hline Female & 54.63 & $50.69^{*}$ \\
\hline Age (years) $\dagger$ & $56.56(4.31)$ & $56.30^{*}(4.24)$ \\
\hline Whitet & 81.48 & $100.00^{*}$ \\
\hline \multicolumn{3}{|l|}{ Educationt } \\
\hline Incomplete high school & 20.24 & $6.67^{*}$ \\
\hline High school & 34.06 & 36.18 \\
\hline$>$ High school & 45.70 & 57.16 \\
\hline ApoE $\varepsilon 4$ allelet & 30.00 & 28.84 \\
\hline \multicolumn{3}{|l|}{ Smoking statust } \\
\hline Never smoker & 44.54 & $40.40^{*}$ \\
\hline Former smoker & 35.55 & 41.82 \\
\hline Current smoker & 19.91 & 17.78 \\
\hline Alcohol $\left(g_{\text {day }}^{-1}\right) \dagger$ & $5.88(12.67)$ & $8.08^{*}(13.47)$ \\
\hline Caffeine $\left(\mathrm{mg} \mathrm{day}^{-1}\right) \dagger$ & $291.04(290.82)$ & $348.08 *(325.93)$ \\
\hline Physical activity scalet & $7.06(1.39)$ & $7.33^{*}(1.33)$ \\
\hline Body mass index $\left(\mathrm{kg} \mathrm{m}^{-2}\right) \dagger$ & $27.48(4.96)$ & $27.17^{*}(4.41)$ \\
\hline Total energy intake $\left(\mathrm{kcal}\right.$ day $\left.^{-1}\right) \dagger$ & $1579(571)$ & 1581 (559) \\
\hline Vitamin A $\left(1000 \times 1 \mathrm{IU} \mathrm{day}^{-1}\right) \dagger$ & $9.13(6.97)$ & $8.65^{*}(6.83)$ \\
\hline Vitamin $\mathrm{B}_{6}\left(\mathrm{mg} \mathrm{day}^{-1}\right) \dagger$ & $1.75(0.67)$ & $1.74^{*}(0.66)$ \\
\hline Vitamin $\mathrm{B}_{12}\left(\mu \mathrm{g}_{\text {day }}{ }^{-1}\right) \dagger$ & $7.61(4.23)$ & $7.06^{*}(3.50)$ \\
\hline Vitamin $C\left(\mathrm{mg} \mathrm{day}^{-1}\right)+$ & $122.39(80.92)$ & $112.67^{*}(69.95)$ \\
\hline Vitamin $E\left(\mathrm{mg} \mathrm{day}^{-1}\right) \dagger$ & $4.97(3.11)$ & $4.66^{\star}(3.01)$ \\
\hline Folate $\left(\mu\right.$ g day $\left.^{-1}\right) \dagger$ & $232.59(101.18)$ & $218.48^{*}(94.97)$ \\
\hline Hypertensiveł & 56.01 & $49.27^{*}$ \\
\hline \multicolumn{3}{|l|}{ Baseline cognitive scores (visit 2)§ } \\
\hline DWRT & $6.61(1.46)$ & $6.78^{*}(1.43)$ \\
\hline DSST/WAIS-R & $45.02(13.01)$ & $51.65^{\star}(10.15)$ \\
\hline WFT & $33.77(12.06)$ & $37.59^{*}(11.52)$ \\
\hline \multicolumn{3}{|l|}{ Cognitive change (visit 4-visit 2)§ } \\
\hline DWRT & $-0.17(1.56)$ & $-0.21(1.50)$ \\
\hline DSST/WAIS-R & $-2.80(6.79)$ & $-4.45^{\star}(6.36)$ \\
\hline WFT & $-0.77(7.86)$ & $-1.84^{*}(7.78)$ \\
\hline
\end{tabular}

ARIC - Atherosclerosis Risk in Communities study; ApoE - apolipoprotein E; DWRT - Delayed Word Recall Test; DSST/WAIS-R - Digit Symbol Substitution Test of the Wechsler Adult Intelligence Scale-Revised; WFT - Word Fluency Test.

Data are mean (standard deviation) or \%

${ }^{\star} P<0.05$ for null hypothesis that means or proportions are equal between plasma and non-plasma groups.

t Covariate measured at visit 1.

‡Covariate measured at visits 1 to 4 : period prevalence over 9 years.

$\S$ Covariate with other time frame.

Table 2 Distribution of fatty acid groups and ratios for $Q_{1}, M, N, Q_{2}$ and $Q_{3}$ : mean (SD); ARIC, 1987-1995

\begin{tabular}{|c|c|c|c|c|c|}
\hline \multirow[b]{2}{*}{ Fatty acid groups and ratios $(j)$} & \multirow{2}{*}{$\frac{Q_{1}}{(N=7814)}$} & M & $\mathrm{N}$ & $\mathrm{Q}_{2}$ & $\mathrm{Q}_{3}$ \\
\hline & & \multicolumn{2}{|c|}{$(N=2251)$} & \multicolumn{2}{|c|}{$(N=634)$} \\
\hline $3 P$ & $0.41(0.09)$ & $0.41(0.10)$ & $0.14(0.05)$ & $0.40(0.09)$ & $0.41(0.10)$ \\
\hline $3 \mathrm{H}$ & $0.18(0.16)$ & $1.01(0.39)$ & $3.44(1.05)$ & $0.17(0.15)$ & 0.16() 0.15 \\
\hline 3 & $0.60(0.19)$ & $1.42(0.43)$ & 3.59 (1.05) & $0.57(0.18)$ & $0.57(0.180$ \\
\hline $3 \mathrm{P} / 6 \mathrm{P}$ & $0.10(0.04)$ & $0.01(0.00)$ & $0.01(0.00)$ & $0.10(0.02)$ & $0.11(0.05)$ \\
\hline $3 \mathrm{H} / 6 \mathrm{H}$ & $2.27(1.87)$ & $0.11(0.05)$ & $0.22(0.08)$ & $2.22(1.71)$ & $2.12(1.69)$ \\
\hline $3 / 6$ & $0.15(0.07)$ & $0.02(0.01)$ & $0.09(0.03)$ & $0.14(0.07)$ & $0.15(0.07)$ \\
\hline $3 \mathrm{H}\left(\mathrm{g} \mathrm{day}^{-1}\right)$ & $0.30(0.28)$ & - & - & $0.28(0.26)$ & $0.27(0.29)$ \\
\hline
\end{tabular}

SD - standard deviation; ARIC - Atherosclerosis Risk in Communities study; $\mathrm{Q}_{1}$ - food-frequency questionnaire measurement at visit 1 of fatty acid group intake as \% of energy intake or ratio of $n-3$ to $n-6$ groups; $\mathrm{M}$ - biomarker of fatty acid intake in cholesteryl ester fraction of plasma; $\mathrm{N}-$ biomarker of fatty acid intake in phospholipid fraction of plasma; $Q_{2}-$ repeat of $Q_{1}$ measured at visit 2 among a subset of the cohort; $Q_{3}-$ repeat of $Q_{1}$ measured at visit 3 among the surviving baseline cohort; fatty acid exposure categories defined under 'Exposure assessment' in Data and methods section.

calibrated estimates. In a few instances significance of odds ratios was preserved, such as in the case of $3 \mathrm{H}, 3 \mathrm{H}$ $\left(\mathrm{g} \mathrm{day}^{-1}\right.$ ), 3 and $3 \mathrm{H} / 6 \mathrm{H}$ with WFT decline as the outcome among the hypertensive stratum (data not shown). In these four exposures, the calibrated odds ratio (95\% confidence interval) for WFT decline in the hypertensive stratum was $0.68(0.49-0.95), 0.69$ (0.47-1.00), 0.65 (0.43-1.00) and $0.70(0.52-0.95)$, respectively. Using SIMEX for selected associations, similar results were obtained. Figure 1 shows two examples of stratified 
Table 3 Multivariate logistic models of cognitive decline and dietary $n-3$ fatty acid exposurestł: naive and regression calibrated OR (95\% CI); ARIC, 1987-1998

\begin{tabular}{|c|c|c|c|c|c|c|c|c|}
\hline \multirow[b]{3}{*}{ Dietary fatty acids $(N=7814)$} & \multicolumn{8}{|c|}{ Statistically reliable cognitive decline $(\mathrm{RCl}<-1.645)$} \\
\hline & \multicolumn{2}{|c|}{ DWRT } & \multicolumn{2}{|c|}{ DSST/WAIS-R } & \multicolumn{2}{|c|}{ WFT } & \multicolumn{2}{|c|}{ GCD } \\
\hline & Naive & RCAL§ & Naive & RCAL & Naive & RCAL & Naive & RCAL \\
\hline & \multicolumn{2}{|c|}{ Models 1a-1g } & \multicolumn{2}{|c|}{ Models 2a-2g } & \multicolumn{2}{|c|}{ Models $3 a-3 g$} & \multicolumn{2}{|c|}{ Models 4.1a-4.1g } \\
\hline$Q_{3 P}$ & $1.02(0.93-1.12)$ & $1.02(0.78-1.34)$ & $0.96(0.87-1.07)$ & $0.89(0.66$ & 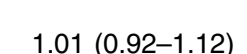 & $1.22(0.9$ & 0.98 & $1.00(0.7$ \\
\hline $3 \mathrm{H}$ & $0.90^{*}(0.81-1.00)$ & $0.88(0.72-1.05)$ & $0.93(0.83-1.04)$ & $0.96(0.76-1.22)$ & $0.85^{*}(0.75-0.96)$ & $0.80(0.62-1.04)$ & $0.91(0.82-1.02)$ & $0.89(0.71-1.11)$ \\
\hline 3 & $0.96(0.87-1.06)$ & $0.99(0.81-1.21)$ & $0.90(0.80-1.02)$ & $0.86(0.62-1.18)$ & $0.87^{\star}(0.77-0.98)$ & $0.85(0.62-1.17)$ & $0.90(0.81-1.01)$ & $0.85(0.64-1.13)$ \\
\hline $3 \mathrm{P} / 6 \mathrm{P}$ & $1.01(0.92-1.10)$ & $1.00(0.81-1.23)$ & $1.04(0.94-1.15)$ & $1.11(0.89-1.39)$ & $1.01(0.91-1.10)$ & $1.21(0.95-1.53)$ & $1.01(0.92-1.10)$ & $1.08(0.87-1.35)$ \\
\hline $3 \mathrm{H} / 6 \mathrm{H}$ & $0.96(0.87-1.06)$ & $0.96(0.80-1.16)$ & $1.03^{*}(0.93-1.13)$ & $1.16(0.91-1.47)$ & $0.86^{\star}(0.77-0.97)$ & $0.84(0.64-1.10)$ & $0.97(0.88-1.06)$ & $0.94(0.73-1.21)$ \\
\hline $3 / 6$ & $0.92(0.83-1.02)$ & $0.89(0.72-1.08)$ & $1.01(0.92-1.12)$ & $1.09(0.91-1.30)$ & $0.95(0.85-1.06)$ & $1.04(0.85-1.27)$ & $0.98(0.89-1.07)$ & $1.01(0.85-1.21)$ \\
\hline $3 \mathrm{H}\left(\mathrm{g} \mathrm{day}^{-1}\right)$ & $0.91(0.81-1.01)$ & $0.89(0.69-1.13)$ & $0.97(0.87-1.07)$ & $1.09(0.89-1.36)$ & $0.87^{\star *}(0.76-0.99)$ & $0.89(0.66-1.20)$ & $0.96(0.87-1.06)$ & $1.05(0.85-1.30)$ \\
\hline
\end{tabular}

OR - odds ratio; Cl - confidence interval; ARIC - Atherosclerosis Risk in Communities study; RCI - Reliable Change Index; DWRT - Delayed Word Recall Test; DSST/WAIS-R - Digit Symbol Substitution Test of the Wechsler Adult Intelligence Scale-Revised; WFT - Word Fluency Test; GCD - global cognitive decline; $Q_{1}$ - food-frequency questionnaire measurement at visit 1 of fatty acid group intake as \% of energy intake or ratio of $n-3$ to $n-6$ groups; fatty acid exposure categories defined under 'Exposure assessment' in Data and methods section.

${ }^{*} P<0.05$ for testing the null hypothesis that $\beta_{1}=0$. See equations (1) and (2).

${ }^{* *} P<0.10$ for testing the null hypotheses that $\gamma=0$ using the likelihood ratio test. See equation (2).

†Exposures were standardised by subtracting each observation from its mean and dividing it by its standard deviation. Each model (e.g. 1a) has one exposure/outcome pair.

$¥$ Control for confounding was done using backward elimination and an overall change in estimate criterion of $5 \%$. Covariates which changed the estimate of exposure by more than $5 \%$ were retained in the final model. Covariates considered as potential confounders were: sociodemographics (age, sex, education, race); genetic factors (apolipoprotein E $\varepsilon 4$ allele); behavioural factors (smoking, alcohol, caffeine consumption and physical activity) and nutritional factors (body mass index, energy intake, other fatty acids, intake of antioxidants and vitamins $\mathrm{B}_{6}$, $\mathrm{B}_{12}$ and folate). Hypertension was considered as a potential effect modifier in separate models. Multiplicative interaction was tested using the likelihood ratio test at an $\alpha$ level of 0.10 .

$\S$ Regression calibrated OR (adjusted for measurement error in dietary fatty acids) with its $95 \% \mathrm{Cl}$, using replicate dietary fatty acid measures at visits 2 and $3\left(\mathrm{Q}_{2}\right.$ and $\left.\mathrm{Q}_{3}\right)$. 


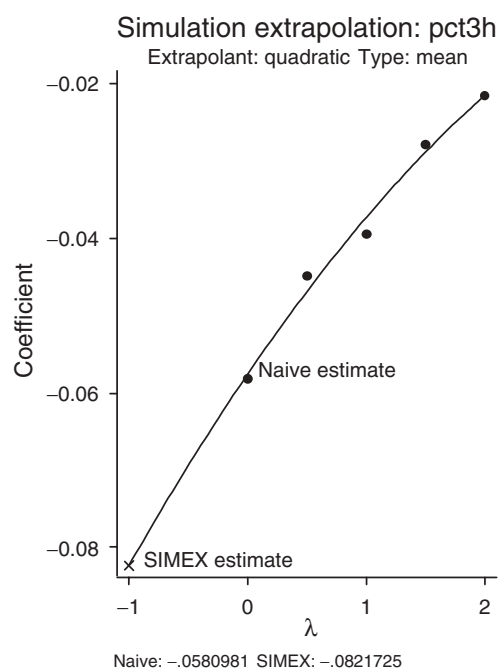

Normotensive stratum

SIMEX OR $(95 \% \mathrm{CI}): 0.92(0.64-1.33)$

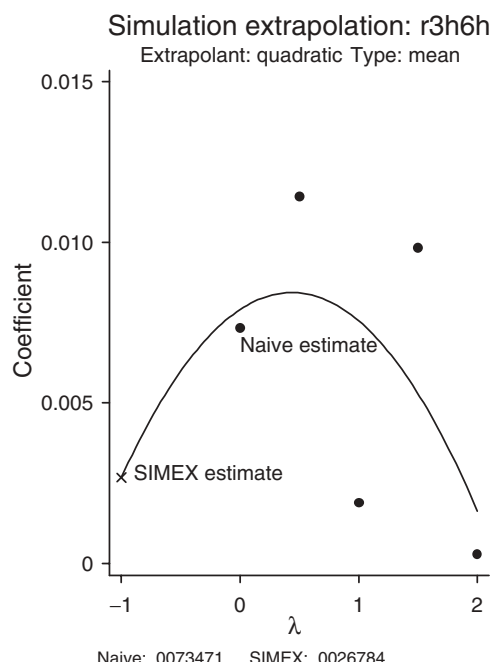

Normotensive stratum

SIMEX OR $(95 \% \mathrm{CI}): 1.00(0.72-1.38)$

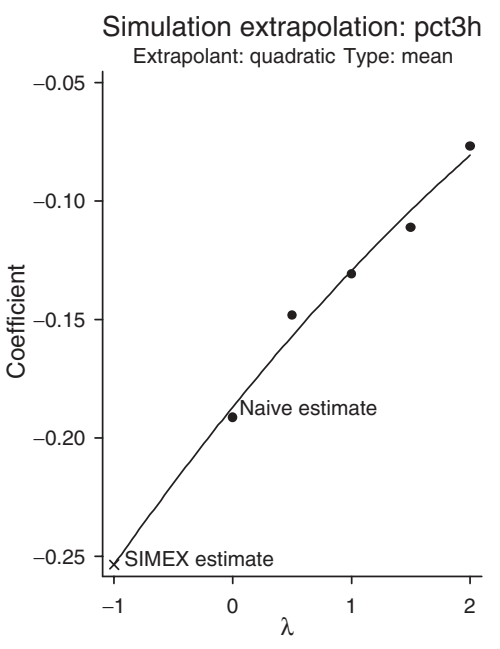

Naive: -.1911881 SIMEX: -.2534457

Hypertensive stratum

SIMEX OR (95\% CI): 0.77 (0.58-1.03)

Simulation extrapolation: r3h6h

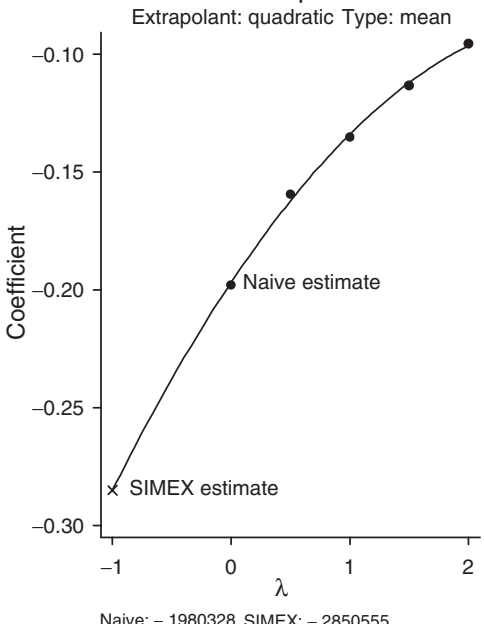

Hypertensive stratum

SIMEX OR (95\% CI): $0.75(0.59-0.97)$

Fig. 1 Simulation extrapolation (SIMEX) plot of corrected coefficients for stratified models $3 \mathrm{~b}$ and $3 \mathrm{e}$ of Table 3; Atherosclerosis Risk in Communities study, 1987-1998. pct3 $\mathrm{h}$ is dietary intake of long-chain $n-3$ fatty acids expressed as \% of energy intake $(3 \mathrm{H})$; r3hr6h is ratio of long-chain $n-3$ to long-chain $n-6$ fatty acids $(3 \mathrm{H} / 6 \mathrm{H})$ (for definition of $3 \mathrm{H}$ and $6 \mathrm{H}$ see 'Exposure assessment' in Data and methods section). $\lambda$ is equivalent to $\theta=\{0.5,1,1.5,2\}$ and is a scale factor used to add error to the covariate and estimate $\beta_{m}=f\left(\theta, \beta_{m}^{59}\right)$ starting from the naive estimate in which $\theta=0$. Hence, the naive estimate of the regression coefficient $\beta$ is the one estimated by generalised linear models without measurement error correction. See Appendix A for more details

models, models $3.2 \mathrm{~b}$ and $3.2 \mathrm{~g}$ of Table 3 (effect of $3 \mathrm{H}$ and $3 \mathrm{H} / 6 \mathrm{H}$ ratio on decline in WFT). The figure shows the extent to which naive estimates are biased towards the null when compared with the corrected regression coefficients using the SIMEX method. This method is described in detail in Appendix A.

\section{Multivariate analysis findings: plasma exposures}

Multivariate logistic regression analyses of the plasma fatty acid data (Table 4) indicated generally lower odds of cognitive decline among subjects with a higher concentration of long-chain $n-3$ fatty acid in their plasma cholesteryl esters and phospholipids, and an elevated ratio of long-chain $n-3 / n-6$ fatty acids. An interaction was noted between WFT for absolute $3 \mathrm{H}$ in cholesteryl esters $(\mathrm{OR}=0.74$ among normotensives vs. 0.51 among hypertensives) without reaching statistical significance at the level of $0.10 \quad(P=0.25)$. The same pattern was observed for the ratio of $3 \mathrm{H} / 6 \mathrm{H}$ in cholesteryl esters and both exposures in the phospholipid fraction. 
Table 4 Multivariate logistic models of cognitive decline and plasma $n-3$ fatty acid exposurestł: OR (95\% Cl) for interaction with hypertensive status; ARIC, 1987-1998

\begin{tabular}{|c|c|c|c|c|}
\hline \multirow[b]{2}{*}{ Plasma fatty acids $(N=2251)$} & \multicolumn{4}{|c|}{ Statistically reliable cognitive decline $(\mathrm{RCl}<-1.645)$} \\
\hline & DWRT & DSST/WAIS-R & WFT & GCD \\
\hline \multicolumn{5}{|l|}{ Plasma cholesteryl esters $\S(\mathrm{M})$} \\
\hline \multicolumn{3}{|l|}{ All subjects } & Models 3.1a-3.1b & Models 4.1a-4.1b \\
\hline $3 \mathrm{H}$ & $1.00(0.82-1.21)$ & $0.91(0.73-1.14)$ & $0.63^{\star}(0.46-0.86)$ & $1.03(0.87-1.22)$ \\
\hline $3 \mathrm{H} / 6 \mathrm{H}$ & $0.92(0.75-1.14)$ & $0.92(0.74-1.15)$ & $0.63^{*}(0.45-0.87)$ & $0.97(0.81-1.16)$ \\
\hline \multicolumn{5}{|l|}{ Normotensive stratum } \\
\hline $3 \mathrm{H}$ & $1.09(0.85-1.40)$ & $0.99(0.74-1.32)$ & $0.74(0.48-1.12)$ & $1.13(0.92-1.38)$ \\
\hline $3 \mathrm{H} / 6 \mathrm{H}$ & $1.02(0.79-1.32)$ & $1.00(0.76-1.32)$ & $0.73(0.48-1.11)$ & $1.09(0.88-1.34)$ \\
\hline \multicolumn{5}{|l|}{ Hypertensive stratum } \\
\hline $3 \mathrm{H}$ & $0.89(0.65-1.21)$ & $0.78(0.55-1.12)$ & $0.51^{*}(0.32-0.83)$ & $0.92(0.69-1.22)$ \\
\hline $3 \mathrm{H} / 6 \mathrm{H}$ & $0.79(0.56-1.13)$ & $0.76(0.51-1.14)$ & $0.51^{*}(0.31-0.84)$ & $0.78(0.55-1.11)$ \\
\hline \multicolumn{5}{|l|}{ Plasma phospholipids $\S(\mathrm{N})$} \\
\hline & Models 1.2a-1.2b & Models 2.2a-2.2b & Models 3.2a-3.2b & Models $4.2 a-4.2 b$ \\
\hline \multicolumn{5}{|l|}{ All subjects } \\
\hline $3 \mathrm{H}$ & $0.93(0.76-1.14)$ & $1.04(0.87-1.24)$ & $0.77^{\star}(0.61-0.97)$ & $0.96(0.80-1.15)$ \\
\hline $3 \mathrm{H} / 6 \mathrm{H}$ & $0.89(0.73-1.10)$ & $0.99(0.82-1.20)$ & $0.72^{\star}(0.55-0.94)$ & $0.93(0.77-1.13)$ \\
\hline \multicolumn{5}{|l|}{ Normotensive stratum } \\
\hline $3 \mathrm{H}$ & $1.03(0.77-1.36)$ & $1.07(0.83-1.39)$ & $0.83(0.60-1.15)$ & $1.03(0.77-1.36)$ \\
\hline $3 \mathrm{H} / 6 \mathrm{H}$ & $0.99(0.75-1.30)$ & $1.06(0.83-1.37)$ & $0.80(0.57-1.13)$ & $1.04(0.80-1.35)$ \\
\hline \multicolumn{5}{|l|}{ Hypertensive stratum } \\
\hline $3 \mathrm{H}$ & $0.83(0.61-1.11)$ & $0.97(0.75-1.26)$ & $0.74(0.53-1.04)$ & $0.94(0.73-1.22)$ \\
\hline $3 \mathrm{H} / 6 \mathrm{H}$ & $0.77(0.56-1.08)$ & $0.89(0.66-1.21)$ & $0.66^{\star}(0.43-0.99)$ & $0.86(0.64-1.15)$ \\
\hline
\end{tabular}

OR - odds ratio; $\mathrm{Cl}$ - confidence interval; ARIC - Atherosclerosis Risk in Communities study; RCI - Reliable Change Index; DWRT - Delayed Word Recall Test; DSST/WAIS-R - Digit Symbol Substitution Test of the Wechsler Adult Intelligence Scale-Revised; WFT - Word Fluency Test; GCD - global cognitive decline; fatty acid exposure categories defined under 'Exposure assessment' in Data and methods section.

${ }^{*} P<0.05$ for testing the null hypothesis that $\beta_{1}=0$. See equations (1) and (2).

tExposures were standardised by subtracting each observation from its mean and dividing it by its standard deviation (SD). Each model (e.g. 1.1a) has one exposure/outcome pair. These models are then stratified by hypertensive status for each of the two exposures.

¥ Same analytic approach was used as in Table 3.

§Plasma cholesteryl ester levels of fatty acids (\%); plasma phospholipids levels of fatty acids (\%); $\mathrm{M}$ and $\mathrm{N}$ in reference to SD values from Table 2.

\section{Discussion}

This population-based prospective study conducted among middle-aged men and women at baseline showed that increased dietary intake of long-chain $n-3$ fatty acids and balancing long-chain $n-3 / n-6$ decreased the risk of cognitive decline in verbal fluency, particularly among hypertensive subjects. This finding also held for the corresponding plasma analytes in the cholesteryl ester and phospholipid fractions. This finding may be due to the higher sensitivity of WFT to early mental decline (i.e. among those aged 55 years or more at baseline) compared with DWRT and DSST/WAIS- $\mathrm{R}^{18}$. Limitations of the study include the lack of psychometric diagnosis for mild cognitive impairment, which might have been a more definite and clinically relevant outcome $^{40}$. However, the neuropsychological tests used represent some of the domains reported to be most sensitive in discriminating between normal ageing and mild cognitive impairment ${ }^{41}$. Another limitation relates to the nature of dietary exposures in general, which are often prone to measurement error both in terms of validity and short-term reliability. We corrected for validity by using replicate FFQ measures but failed to correct for short-term reliability of the FFQ due to the lack of adequate short-term replicates in ARIC. Nevertheless, a previous study by Ma et $\mathrm{al}^{27}$ provides estimates of short-term reliability for each of the fatty acids that were considered. Moreover, residual confounding due to inadequate control or measurement of potential confounders cannot be totally ruled out. It is important to note also that exposure timing ( 1 year prior to visit 1 ) did not coincide with the baseline measurement of outcome (visit 2), which constitutes another major limitation.

One of the main strengths of this study is its prospective design which, as stated earlier, thus far is unique in the literature testing this particular hypothesis ${ }^{42}$. An evidence-based report suggested a need to look for the effect of $n-3$ fatty acids on cognitive decline by cardiovascular disease status and to define exposure in terms of absolute value of medium- and long-chain fatty acids, as well as the ratio between $n-3$ and $n-6$ fatty acids in diet and plasma ${ }^{43}$. All of these suggestions were implemented in the present study. Moreover, this is the first study to assess effect modification by hypertensive status and to test at the population level a biological interaction documented in animal experimental work. Measurement error, which almost always accompanies dietary assessment, was corrected for in this study using RCAL for all associations and SIMEX for a selected number of these associations. 
Previous epidemiological studies have shown that the fatty acids composition of plasma differs significantly between subjects with normal cognitive functioning and patients with some form of cognitive impairment ${ }^{4-46}$. While the majority showed a beneficial effect of plasma and erythrocyte $n-3$ fatty acids on cognition, a casecontrol study - the Canadian Study of Health and Ageing - reported that the mean relative plasma concentration of $n-3$ fatty acids as well as total PUFAs was higher among subjects aged 65 years or more with cognitive impairment or dementia after controlling for demographic, behavioural and genetic factors ${ }^{47}$. Epidemiological studies based on dietary assessments of $n-3$ fatty acids also had suggestive but somewhat controversial results. While most leaned towards a protective effect of increasing intake of these fatty acids in the diet ${ }^{2,3,48-50}$, others found no effect or the opposite effect on cognitive functioning and decline ${ }^{4,51}$.

One possibly important implication from our study's results is that diets rich in fatty acids of marine origin should be considered for middle-aged subjects. We explored whether such an association was differential according to hypertensive status. Although no statistically significant interactions were found, the results suggest that hypertensive subjects (e.g. odds ratios for $3 \mathrm{H}$ and WFT were $<1$ with $P<0.05$ ) may benefit from supplementation of their diets to a larger extent than the normotensive group. These results merit replication given the large public health potential that would be associated with results that unequivocally indicate an inverse association between fatty acid intake and reduced cognitive decline in the general population. The literature indicates that these fatty acids were frequently found associated with reduced risk of cardiovascular disease, including stroke ${ }^{52}$ and coronary heart disease $\mathrm{e}^{53,54}$, although thus far all the evidence is of an observational nature. They have also been associated with improved insulin sensitivity ${ }^{55}$, reduced risk of dyslipidaemia $^{56}$ and a hypocoagulable profile ${ }^{57}$ among other health benefits. Because many of these conditions are also related to cognitive impairment, future research should focus on disentangling the direct and indirect effects of fatty acids (using plasma biomarkers) on cognition and uncover the main mechanism involved in their ability to prevent clinically significant decline in ageing populations. Finally, these findings suggest the utility of randomised clinical trials that would augment intake of marine fatty acids in the treatment group and give a nonenriched diet to the placebo group while allowing for stratification by baseline hypertensive status.

\section{Acknowledgements}

Sources of funding: ARIC is carried out as a collaborative study supported by the National Heart, Lung, and Blood Institute, contracts N01-HC-55015, N01-HC-55016,
N01-HC-55018, N01-HC-55019, N01-HC-55020, N01-HC55021 and N01-HC-55022.

Conflict of interest declaration: None.

Authorship responsibilities: M.A.B. contributed to conceptualisation, literature review, statistical analysis and data management, write-up of the manuscript. J.S.K. contributed to statistical and epidemiological methods, literature review, write-up of parts of the manuscript, final revision of the manuscript. P.D.S. made substantive contribution in the area of cognitive decline and conceptualisation of outcome variables, literature review, revision of the final manuscript. G.H. contributed to dataset/variable acquisition, operationalisation and management, write-up of parts of the manuscript, revision of the final manuscript. J.I. contributed to write-up on parts on measurement error adjustment methods, revision of the final manuscript.

Acknowledgements: The authors thank all ARIC staff and participants for their important contributions; Aaron Folsom (University of Minnesota, Twin Cities, Department of Epidemiology and ARIC principal investigator) for making available to us the plasma fatty acid data for the Minneapolis baseline population of ARIC; William EM Lands for his assistance in clarifying concepts related to his previously published empirical equations and the classification of fatty acid groups; and Eliseo Guallar and Woody Chambless for giving us primary and statistical reviews on the manuscript through the ARIC publication committee.

\section{References}

1 United Nations (UN). World Population Prospects: The 2002 Revision. New York: UN, 2002.

2 Morris MC, Evans DA, Bienias JL, Tangney CC, Bennett DA, Wilson RS, et al. Consumption of fish and $n-3$ fatty acids and risk of incident Alzheimer disease. Archives of Neurology 2003; 60(7): 940-6.

3 Kalmijn S, van Boxtel MP, Ocke M, Verschuren WM, Kromhout D, Launer LJ. Dietary intake of fatty acids and fish in relation to cognitive performance at middle age. Neurology 2004; 62(2): 275-80.

4 Kalmijn S, Feskens EJ, Launer LJ, Kromhout D. Polyunsaturated fatty acids, antioxidants, and cognitive function in very old men. American Journal of Epidemiology 1997; 145(1): 33-41.

5 Youdim KA, Martin A, Joseph JA. Essential fatty acids and the brain: possible health implications. International Journal of Developmental Neuroscience 2000; 18(4-5): 383-99.

6 Haag M. Essential fatty acids and the brain. Canadian Journal of Psychiatry 2003; 48(3): 195-203.

7 de Wilde MC, Hogyes E, Kiliaan AJ, Farkas T, Luiten PG, Farkas E. Dietary fatty acids alter blood pressure, behavior and brain membrane composition of hypertensive rats. Brain Research 2003; 988(1-2): 9-19.

8 Frenoux JM, Prost ED, Belleville JL, Prost JL. A polyunsaturated fatty acid diet lowers blood pressure and improves antioxidant status in spontaneously hypertensive rats. Journal of Nutrition 2001; 131(1): 39-45.

9 Bellenger-Germain S, Poisson JP, Narce M. Antihypertensive effects of a dietary unsaturated FA mixture in spontaneously hypertensive rats. Lipids 2002; 37(6): 561-7. 
10 Engler MM, Engler MB, Pierson DM, Molteni LB, Molteni A. Effects of docosahexaenoic acid on vascular pathology and reactivity in hypertension. Experimental Biology and Medicine 2003; 228(3): 299-307.

11 The ARIC investigators. The Atherosclerosis Risk in Communities (ARIC) Study: design and objectives. American Journal of Epidemiology 1989; 129(4): 687-702.

12 Abate C, Ferrari-Ramondo V, Di Iorio A. Risk factors for cognitive disorders in the elderly: a review. Archives of Gerontology and Geriatrics 1998; (Suppl. 6): 7-15.

13 Knopman DS, Ryberg S. A verbal memory test with high predictive accuracy for dementia of the Alzheimer type. Archives of Neurology 1989; 46(2): 141-5.

14 Wechsler D. WAIS-R Manual. Cleveland, OH: The Psychological Corporation, 1981

15 Lezak MD. Neuropsychological Assessment, 2nd ed. New York: Oxford University Press, 1983.

16 Russell EW. WAIS factor analysis with brain-damaged subjects using criterion measures. Journal of Consulting and Clinical Psychology 1972; 39(1): 133-9.

17 Tranel D. Neuropsychological assessment. Psychiatric Clinics of North America 1992; 15(2): 283-99.

18 Benton AL, Eslinger PJ, Damasio AR. Normative observations on neuropsychological test performances in old age. Journal of Clinical Neuropsychology 1981; 3(1): 33-42.

19 Franzen MD, ed. Mutlilingual Aphasia Examination. Kansas City, MO: Test Corporation of America, 1986.

20 Frerichs RJ, Tuokko HA. Reliable change scores and their relation to perceived change in memory: implications for the diagnosis of mild cognitive impairment. Archives of Clinical Neuropsychology 2006; 21(1): 109-15.

21 Mueller CW, Kim JO. Factor Analysis: Statistical Methods and Practical Issues. London: Sage Publications, 1978.

22 Willett WC, Sampson L, Stampfer MJ, Rosner B, Bain C, Witschi J, et al. Reproducibility and validity of a semiquantitative food frequency questionnaire. American Journal of Epidemiology 1985; 122(1): 51-65.

23 Lands WE, Libelt B, Morris A, Kramer NC, Prewitt TE, Bowen $\mathrm{P}$, et al. Maintenance of lower proportions of $(n-6)$ eicosanoid precursors in phospholipids of human plasma in response to added dietary $(n-3)$ fatty acids. Biochimica et Biophysica Acta 1992; 1180(2): 147-62.

24 Lands WE. Long-term fat intake and biomarkers. American Journal of Clinical Nutrition 1995; 61(3 Suppl.): 721S-5S.

25 Willett WC. Nutritional Epidemiology. New York: Oxford University Press, 1990.

26 Shahar E, Boland LL, Folsom AR, Tockman MS, McGovern PG, Eckfeldt JH. Docosahexaenoic acid and smokingrelated chronic obstructive pulmonary disease. The Atherosclerosis Risk in Communities Study Investigators. American Journal of Respiratory and Critical Care Medicine 1999; 159(6): 1780-5.

27 Ma J, Folsom AR, Eckfeldt JH, Lewis L, Chambless LE. Shortand long-term repeatability of fatty acid composition of human plasma phospholipids and cholesterol esters. The Atherosclerosis Risk in Communities (ARIC) Study Investigators. American Journal of Clinical Nutrition 1995; 62(3): 572-8.

28 Baecke JA, Burema J, Frijters JE. A short questionnaire for the measurement of habitual physical activity in epidemiological studies. American Journal of Clinical Nutrition 1982; 36(5): 936-42.

29 Richardson MT, Ainsworth BE, Wu HC, Jacobs Jr DR, Leon AS. Ability of the Atherosclerosis Risk in Communities (ARIC)/Baecke Questionnaire to assess leisure-time physical activity. International Journal of Epidemiology 1995; 24(4): 685-93.

30 Cerhan JR, Folsom AR, Mortimer JA, Shahar E, Knopman DS, McGovern PG, et al. Correlates of cognitive function in middle-aged adults. Atherosclerosis Risk in Communities
(ARIC) Study Investigators. Gerontology 1998; 44(2): 95-105.

31 Peacock JM, Folsom AR, Knopman DS, Mosley TH, Goff DC Jr, Szklo M. Dietary antioxidant intake and cognitive performance in middle-aged adults. The Atherosclerosis Risk in Communities (ARIC) Study investigators. Public Health Nutrition 2000; 3(3): 337-43.

32 Knopman D, Boland LL, Mosley T, Howard G, Liao D, Szklo $\mathrm{M}$, et al. Cardiovascular risk factors and cognitive decline in middle-aged adults. Neurology 2001; 56(1): 42-8.

33 Blair CK, Folsom AR, Knopman DS, Bray MS, Mosley TH, Boerwinkle E. APOE genotype and cognitive decline in a middle-aged cohort. Neurology 2005; 64(2): 268-76.

34 Maldonado G, Greenland S. Simulation study of confounder-selection strategies. American Journal of Epidemiology 1993; 138(11): 923-36.

35 Selvin S. Statistical Analysis of Epidemiologic Data, 3rd ed. New York: Oxford University Press, 2004

36 Hernan MA, Hernandez-Diaz S, Werler MM, Mitchell AA. Causal knowledge as a prerequisite for confounding evaluation: an application to birth defects epidemiology. American Journal of Epidemiology 2002; 155(2): 176-84.

37 Hardin JW, Schemiediche H, Carroll RJ. The simulation extrapolation method for fitting generalized linear models with additive measurement error. The STATA Journal 2003; 4: 373-85.

38 Hardin JW, Schmiediche H, Carroll RJ. The regression calibration method for fitting generalized linear models with additive measurement error. The STATA Journal 2003; 4: 1-12.

39 Stata Corporation. Statistics/Data Analysis: Release 8.2 [program]. College Station, TX: Stata Corporation, 2002.

40 Petersen RC, Smith GE, Waring SC, Ivnik RJ, Tangalos EG, Kokmen E. Mild cognitive impairment: clinical characterization and outcome. Archives of Neurology 1999; 56(3): 303-8.

41 Ritchie K, Artero S, Touchon J. Classification criteria for mild cognitive impairment: a population-based validation study. Neurology 2001; 56(1): 37-42.

42 Solfrizzi V, D'Introno A, Colacicco AM, Capurso C, Del Parigi A, Capurso S, et al. Dietary fatty acids intake: possible role in cognitive decline and dementia. Experimental Gerontology 2005; 40(4): 257-70.

43 Maclean CH, Issa AM, Newberry SJ, Mojica WA, Morton SC, Garland RH, et al. Effects of omega-3 fatty acids on cognitive function with aging, dementia, and neurological diseases. Evidence Report/Technology Assessment (Summary) 2005; (114): 1-3.

44 Conquer JA, Tierney MC, Zecevic J, Bettger WJ, Fisher RH. Fatty acid analysis of blood plasma of patients with Alzheimer's disease, other types of dementia, and cognitive impairment. Lipids 2000; 35(12): 1305-12.

45 Heude B, Ducimetiere P, Berr C. Cognitive decline and fatty acid composition of erythrocyte membranes - The EVA Study. American Journal of Clinical Nutrition 2003; 77(4): 803-8.

46 Tully AM, Roche HM, Doyle R, Fallon C, Bruce I, Lawlor B, et al. Low serum cholesteryl ester-docosahexaenoic acid levels in Alzheimer's disease: a case-control study. British Journal of Nutrition 2003; 89(4): 483-9.

47 Laurin D, Verreault R, Lindsay J, Dewailly E, Holub BJ. Omega-3 fatty acids and risk of cognitive impairment and dementia. Journal of Alzheimer's Disease 2003; 5(4): 315-22.

48 Kalmijn S, Launer LJ, Ott A, Witteman JC, Hofman A, Breteler MM. Dietary fat intake and the risk of incident dementia in the Rotterdam Study. Annals of Neurology 1997; 42(5): 776-82.

49 Whalley LJ, Fox HC, Wahle KW, Starr JM, Deary IJ. Cognitive aging, childhood intelligence, and the use of food 
supplements: possible involvement of $n-3$ fatty acids. American Journal of Clinical Nutrition 2004; 80(6): 1650-7.

50 Morris MC, Evans DA, Tangney CC, Bienias JL, Wilson RS. Fish consumption and cognitive decline with age in a large community study. Archives of Neurology 2005; 62(12): 1849-53.

51 Engelhart MJ, Geerlings MI, Ruitenberg A, Van Swieten JC, Hofman A, Witteman JC, et al. Diet and risk of dementia: does fat matter? The Rotterdam Study. Neurology 2002; 59(12): 1915-21.

52 He K, Song Y, Daviglus ML, Liu K, Van Horn L, Dyer AR, et al. Fish consumption and incidence of stroke: a metaanalysis of cohort studies. Stroke 2004; 35(7): 1538-42.

53 Whelton SP, He J, Whelton PK, Muntner P. Meta-analysis of observational studies on fish intake and coronary heart disease. American Journal of Cardiology 2004; 93(9): 1119-23.

54 He K, Song Y, Daviglus ML, Liu K, Van Horn L, Dyer AR, et al. Accumulated evidence on fish consumption and coronary heart disease mortality: a meta-analysis of cohort studies. Circulation 2004; 109(22): 2705-11.

55 Feskens EJ, Virtanen SM, Rasanen L, Tuomilehto J, Stengard J, Pekkanen J, et al. Dietary factors determining diabetes and impaired glucose tolerance. A 20-year follow-up of the Finnish and Dutch cohorts of the Seven Countries Study. Diabetes Care 1995; 18(8): 1104-12.

56 Harris WS, Windsor SL, Dujovne CA. Effects of four doses of $n-3$ fatty acids given to hyperlipidemic patients for six months. Journal of the American College of Nutrition 1991; 10(3): 220-7.

57 Shahar E, Folsom AR, Wu KK, Dennis BH, Shimakawa T, Conlan MG, et al. Associations of fish intake and dietary $n-3$ polyunsaturated fatty acids with a hypocoagulable profile. The Atherosclerosis Risk in Communities (ARIC) Study. Arteriosclerosis and Thrombosis 1993; 13(8): 1205-12.

58 Carroll RJ, Ruppert D, Stefanski LA. Measurement Error in Nonlinear Models. Boca Raton, FL: CRC Press, 1995.

59 Holcomb JP Jr. Regression with covariates and outcome calculated from a common set of variables measured with error: estimation using the SIMEX method. Statistics in Medicine 1999; 18(21): 2847-62.

\section{Appendix A - Measurement error correction}

We considered a structural model in which $i$ stands for individual and $j$ for dietary variable and $T_{i j}$ (a latent variable) is the true value of dietary intake of nutrient or ratio of nutrients $j$ for subject $i$. For that subject $i, Q_{i j}$ is the value of dietary variable $j$ derived from the FFQ. $Q_{1 i j}$ and their replicate values from visits 2 and $3, Q_{2 i j}$ and $Q_{3 i j}$, were entered into the model as $Z$-scored manifest variables.

$$
\begin{aligned}
& Q_{1 i j}=\alpha_{01 Q_{1 j}}+\alpha_{11 Q_{1 j}} T_{i j}+\varepsilon_{Q_{1 i j}} \\
& Q_{2 i j}=\alpha_{02 Q_{2 j}}+\alpha_{12 Q_{2 j}} T_{i j}+\varepsilon_{Q_{2 i j}} \\
& Q_{3 i j}=\alpha_{03 Q_{3 j}}+\alpha_{13 Q_{3 j}} T_{i j}+\varepsilon_{Q_{3} i j}
\end{aligned}
$$

An estimate of the error variance covariance matrix $\hat{\Sigma}_{\text {uu }}$ was computed using a formula suggested previously ${ }^{35}$, which takes into account the intra-class correlation between replicate measures. For RCAL and SIMEX, the method of moments is used to correct for measurement error in covariates and can be summarised as follows ${ }^{39,58}$ :

$$
\left(\begin{array}{l}
\hat{\beta}_{Z, R C} \\
\hat{\beta}_{T, R C}
\end{array}\right)=\left(\begin{array}{cc}
\Sigma_{Z Z} & \Sigma_{Z Q} \\
\Sigma_{Q Z} & \Sigma_{Q Q}-\hat{\Sigma}_{\mathrm{uu}}
\end{array}\right)^{-1}\left(\begin{array}{cc}
\Sigma_{Z Z} & \Sigma_{Z Q} \\
\Sigma_{Q Z} & \Sigma_{Q Q}
\end{array}\right)\left(\begin{array}{l}
\hat{\beta}_{Z, \text { naive }} \\
\hat{\beta}_{T, \text { naive }}
\end{array}\right) .
$$

The generalised linear model in which measurement error correction of covariates is conducted can be written as:

$$
\mathrm{E}\left(Y \mid Q_{j}, Z_{k}\right)=\hat{\beta}_{O}+\sum_{j=1}^{m} \hat{\beta}_{T, \text { naive }, k} Q_{j}+\sum_{k=1}^{n} \hat{\beta}_{Z, \text { naive }, k} Q_{k} .
$$

SIMEX is a procedure consisting of four main steps.

Step 1. Fitting the causal model to obtain the estimated coefficients $\beta_{\text {naive }}$ and an estimate of the measurement error variance $\sigma_{\mathrm{u}}^{2}$.

Step 2. Generating random pseudo errors for a scale factor $\theta$ times the estimated error variance, $\varepsilon \sim N\left(0, \theta \sigma_{\mathrm{u}}^{2}\right)$. These pseudo errors are added to the original values of the error-prone covariate. Fitting the model to obtain $\beta$ nnaive, $\theta_{j}$ \}. This is repeated $r$ times to obtain the mean coefficient vector, $\beta\left\{\theta_{j}\right\}=(1 / r) \sum \beta\left\{i, \theta_{j}\right\}$.

Step 3. The previous step is repeated for $j=1, \ldots, k^{*}$ scale factors, where typically we use $\theta=\{0.5,1,1.5,2\}$, although individual researchers may choose a longer list of scale factors. Using the typical list of scale factors we have $k=5$ estimated coefficient vectors, since $k^{*}=4$ for the list above and we have the estimated coefficient vector from the initial step $\left(k=k^{*}+1\right)$.

Step 4. For each regression coefficient $\beta_{m}$ $(m=1, \ldots, p)$ in the model, we consider the estimated coefficient as a function of the scale factor $\theta_{j}$ for $j=1, \ldots, k$. Formally, we specify a function $\mathrm{f}(\mathrm{)})$ such that $\beta_{m}=\mathrm{f}\left(\theta, \beta_{m}^{\{\theta\}}\right)$. We estimate this relationship and then extrapolate back the final estimates $\beta_{m}=\mathrm{f}\left(\theta_{0}=-1, \beta_{m}^{\{\theta\}}\right)$ (no measurement error). Researchers are free to choose the form of the function $\mathrm{f}(\mathrm{)})$, but we point out that there are relatively few - in this case, five - observations available to estimate the parameters of $\mathrm{f}(\mathrm{)}$ ). The function $\mathrm{f}($ ) used to model the relationship between the estimated coefficient and $\theta$ is called the extrapolant function ${ }^{59}$. Although deciding which model to fit is a valid question when performing SIMEX, it has been shown that conservative estimates with a quadratic curve do improve over the naive estimator without any correction. Investigators may also use model-fitting techniques to decide which model to fit and then extrapolate with. Calculating the standard error of the SIMEX estimator requires 100 simulations on its own. With the ever-increasing speed of computers, the necessary computing power is widely available ${ }^{37}$. 
Appendix B - Unadjusted mean (SD) of fatty acid exposures by cognitive decline status in three domains (DWRT, DSST/WAIS-R and WFT) and GCD, stratified by hypertensive status; ARIC, 1987-1998

\begin{tabular}{|c|c|c|c|c|c|c|c|c|c|}
\hline & \multirow[b]{3}{*}{ Mean (SD) } & \multicolumn{8}{|c|}{ Statistically reliable cognitive decline $(\mathrm{RCl}<-1.645)$} \\
\hline & & \multicolumn{2}{|c|}{ DWRT } & \multicolumn{2}{|c|}{ DSST/WAIS-R } & \multicolumn{2}{|c|}{ WFT } & \multicolumn{2}{|c|}{ GCD } \\
\hline & & No & Yes & No & Yes & No & Yes & No & Yes \\
\hline \multicolumn{10}{|l|}{ Dietary intake (\% of energy) } \\
\hline All subjects $(N=7814)$ & & & $n=481$ & & $n=408$ & & $n=392$ & & $n=486$ \\
\hline $3 P$ & $0.415(0.086)$ & 0.415 & 0.416 & 0.415 & 0.412 & 0.415 & 0.416 & 0.414 & 0.413 \\
\hline $3 \mathrm{H}$ & $0.182(0.166)$ & 0.182 & 0.174 & 0.182 & 0.181 & 0.182 & 0.170 & 0.182 & 0.178 \\
\hline 3 & $0.597(0.190)$ & 0.597 & 0.590 & 0.597 & 0.593 & 0.597 & 0.586 & 0.597 & 0.592 \\
\hline $3 \mathrm{P} / 6 \mathrm{P}$ & $0.103(0.037)$ & 0.103 & 0.103 & 0.103 & 0.104 & 0.103 & 0.103 & 0.103 & 0.103 \\
\hline $3 \mathrm{H} / 6 \mathrm{H}$ & $2.272(1.872)$ & 2.277 & 2.199 & 2.269 & 2.320 & 2.284 & $2.052^{*}$ & 2.276 & 2.216 \\
\hline $3 / 6$ & $0.147(0.073)$ & 0.147 & 0.144 & 0.147 & 0.148 & 0.147 & 0.143 & 0.147 & 0.145 \\
\hline $3 \mathrm{H}\left(\mathrm{mg} \mathrm{day}^{-1}\right)$ & $302(283)$ & 302 & 300 & 302 & 294 & 303 & 279 & 302 & 292 \\
\hline Normotensive $(N=3313)$ & & & $n=178$ & & $n=250$ & & $n=212$ & & $n=303$ \\
\hline $3 \mathrm{P}$ & $0.415(0.089)$ & 0.415 & 0.409 & 0.415 & 0.404 & 0.415 & 0.420 & 0.415 & 0.413 \\
\hline $3 \mathrm{H}$ & $0.173(0.162)$ & 0.173 & 0.163 & 0.172 & 0.180 & 0.173 & 0.164 & 0.173 & 0.163 \\
\hline 3 & $0.588(0.187)$ & 0.588 & 0.573 & 0.588 & 0.585 & 0.588 & 0.585 & 0.588 & 0.576 \\
\hline $3 \mathrm{P} / 6 \mathrm{P}$ & $0.101(0.037)$ & 0.101 & 0.099 & 0.101 & 0.101 & 0.101 & 0.102 & 0.101 & 0.099 \\
\hline $3 \mathrm{H} / 6 \mathrm{H}$ & $2.215(1.775)$ & 2.215 & 2.210 & 2.209 & 2.360 & 2.223 & 2.059 & 2.223 & 2.054 \\
\hline $3 / 6$ & $0.142(0.069)$ & 0.142 & 0.137 & 0.142 & 0.142 & 0.142 & 0.141 & 0.143 & 0.135 \\
\hline $3 \mathrm{H}\left(\mathrm{mg} \mathrm{day}^{-1}\right)$ & $286(265)$ & 285 & 299 & 286 & 299 & 286 & 288 & 286 & 289 \\
\hline Hypertensivet $(N=4219)$ & & & $n=286$ & & $n=250$ & & $n=212$ & & $n=303$ \\
\hline $3 \mathrm{P}$ & $0.415(0.085)$ & 0.414 & 0.422 & 0.415 & 0.416 & 0.415 & 0.413 & 0.415 & 0.415 \\
\hline $3 \mathrm{H}$ & $0.189^{*}(0.169)$ & 0.190 & 0.178 & 0.190 & 0.182 & 0.190 & 0.172 & 0.189 & 0.189 \\
\hline 3 & $0.604^{\star}(0.193)$ & 0.604 & 0.600 & 0.605 & 0.599 & 0.605 & 0.584 & 0.604 & 0.603 \\
\hline $3 \mathrm{P} / 6 \mathrm{P}$ & $0.104^{\star}(0.037)$ & 0.104 & 0.106 & 0.104 & 0.106 & 0.104 & 0.102 & 0.104 & 0.105 \\
\hline $3 \mathrm{H} / 6 \mathrm{H}$ & $2.310 *(1.817)$ & 2.328 & 2.188 & 2.331 & 2.130 & 2.334 & $2.025^{\star}$ & 2.328 & 2.194 \\
\hline $3 / 6$ & $0.150^{\star}(0.076)$ & 0.151 & 0.149 & 0.150 & 0.150 & 0.151 & 0.142 & 0.150 & 0.151 \\
\hline $3 \mathrm{H}\left(\mathrm{mg} \mathrm{day}^{-1}\right)$ & $315^{\star}(298)$ & 316 & 300 & 316 & 292 & 318 & $265^{\star}$ & 317 & 300 \\
\hline \multicolumn{10}{|l|}{ Plasma cholesteryl estersł } \\
\hline All subjects $(N=2251)$ & & & $n=123$ & & $n=119$ & & $n=115$ & & $n=140$ \\
\hline $3 \mathrm{H}$ & 1.009 (0.395) & 1.008 & 1.015 & 1.009 & 1.010 & 1.012 & 0.947 & 1.006 & 1.044 \\
\hline $3 \mathrm{H} / 6 \mathrm{H}$ & $0.112(0.047)$ & 0.112 & 0.109 & 0.112 & 0.112 & 0.113 & $0.101^{*}$ & 1.112 & 1.111 \\
\hline Normotensive $(N=1107)$ & & & $n=52$ & & $n=52$ & & $n=52$ & & $n=61$ \\
\hline $3 \mathrm{H}$ & $0.997(0.408)$ & 0.995 & 1.029 & 0.995 & 1.026 & 0.997 & 0.976 & 0.992 & 1.072 \\
\hline $3 \mathrm{H} / 6 \mathrm{H}$ & $0.113(0.048)$ & 0.113 & 0.114 & 0.113 & 0.117 & 0.113 & 0.106 & 0.113 & 0.118 \\
\hline Hypertensive $(N=1075)$ & & & $n=69$ & & $n=64$ & & $n=60$ & & $n=73$ \\
\hline $3 \mathrm{H}$ & $1.024(0.387)$ & 1.026 & 1.004 & 1.026 & 0.991 & 1.030 & $0.922^{*}$ & 1.024 & 1.023 \\
\hline $3 \mathrm{H} / 6 \mathrm{H}$ & $0.112(0.045)$ & 0.113 & 0.106 & 0.113 & 0.107 & 0.113 & $0.097^{*}$ & 0.113 & 0.105 \\
\hline \multicolumn{10}{|l|}{ Plasma phospholipidsł } \\
\hline All subjects $(N=2251)$ & & & $n=123$ & & $n=119$ & & $n=115$ & & $n=140$ \\
\hline $3 \mathrm{H}$ & $3.444(1.053)$ & 3.448 & 3.379 & 3.442 & 3.482 & 3.453 & 3.279 & 3.437 & 3.557 \\
\hline $3 \mathrm{H} / 6 \mathrm{H}$ & $0.222(0.082)$ & 0.223 & 0.214 & 0.222 & 0.222 & 0.223 & $0.206^{*}$ & 0.222 & 0.223 \\
\hline Normotensive $(N=1107)$ & & & $n=52$ & & $n=52$ & & $n=52$ & & $n=61$ \\
\hline $3 \mathrm{H}$ & 3.438 (1.059) & 3.437 & 3.460 & 3.434 & 3.513 & 3.440 & 3.381 & 3.426 & 3.634 \\
\hline $3 \mathrm{H} / 6 \mathrm{H}$ & $0.225(0.084)$ & 0.225 & 0.225 & 0.225 & 0.231 & 0.226 & 0.217 & 0.225 & 0.226 \\
\hline Hypertensive $(N=1075)$ & & & $n=69$ & & $n=64$ & & $n=60$ & & $n=73$ \\
\hline $3 \mathrm{H}$ & $3.458(1.053)$ & 3.468 & 3.314 & 3.460 & 3.433 & 3.472 & 3.218 & 3.454 & 3.518 \\
\hline $3 \mathrm{H} / 6 \mathrm{H}$ & $0.220(0.080)$ & 0.220 & 0.206 & 0.220 & 0.213 & 0.221 & $0.198^{*}$ & 0.220 & 0.213 \\
\hline
\end{tabular}

SD - standard deviation; RCI - Reliable Change Index; DWRT - Delayed Word Recall Test; DSST/WAIS-R - Digit Symbol Substitution Test of the Wechsler Adult Intelligence Scale-Revised; WFT - Word Fluency Test; GCD - global cognitive decline; ARIC - Atherosclerosis Risk in Communities study; fatty acid exposure categories defined under 'Exposure assessment' in Data and methods section.

${ }^{\star} P<0.05$ for null hypothesis that means of exposures are equal to each other between cognitive decline categories or hypertensive status.

t'Hypertensive': screened positive on measured hypertension at either visits 1 to 4 or was taking antihypertensive medication in the two weeks prior to examination at any of the four visits.

‡Plasma cholesteryl ester levels of fatty acids (\%); plasma phospholipids levels of fatty acids (\%). 
Appendix $\mathrm{C}$ - Correlations and mean differences between covariates and main fatty acid exposures among all subjects in the dietary group $(N=7814)$ and the plasma group $(N=2251)$; ARIC, 1987-1998

\begin{tabular}{|c|c|c|c|c|c|c|c|}
\hline & \multicolumn{7}{|c|}{ Dietary fatty acid exposures (\% of total energy intake) } \\
\hline & 3P & $3 \mathrm{H}$ & 3 & $3 \mathrm{P} / 6 \mathrm{P}$ & $3 \mathrm{H} / 6 \mathrm{H}$ & $3 / 6$ & $3 \mathrm{H}\left(\mathrm{mg} \mathrm{day}^{-1}\right)$ \\
\hline Mean (SD) & $0.415(0.086)$ & $0.182(0.166)$ & $0.597(0.190)$ & $0.103(0.037)$ & $2.272(1.872)$ & $0.147(0.073)$ & $302(283)$ \\
\hline 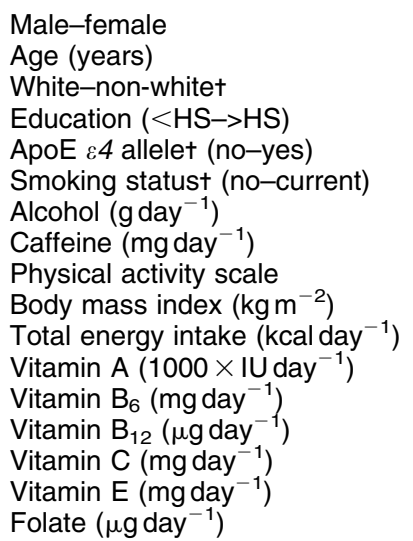 & $\begin{array}{r}0.004^{\star} \\
0.018 \\
0.003 \\
0.011^{\star} \\
0.004^{\star} \\
-0.012^{\star} \\
0.078^{\star} \\
0.037^{\star} \\
-0.024^{\star} \\
0.058^{\star} \\
-0.055^{\star} \\
0.040^{\star} \\
-0.045^{\star} \\
0.103^{\star} \\
-0.143^{\star} \\
-0.048^{\star} \\
-0.055^{\star}\end{array}$ & $\begin{array}{c}-0.004^{\star} \\
-0.010^{\star} \\
0.077^{\star} \\
-0.016^{\star} \\
-0.010^{\star} \\
0.015^{\star} \\
-0.015 \\
-0.103^{\star} \\
0.012 \\
0.057^{\star} \\
-0.160^{\star} \\
0.130^{\star} \\
0.096^{\star} \\
0.171^{\star} \\
0.030^{\star} \\
0.032^{\star} \\
0.042^{\star}\end{array}$ & $\begin{array}{c}-0.036^{\star} \\
-0.008 \\
0.081^{\star} \\
-0.006 \\
-0.005 \\
0.003 \\
0.023^{\star} \\
-0.073^{\star} \\
-0.000 \\
0.076^{\star} \\
-0.164^{\star} \\
0.131^{\star} \\
0.063^{\star} \\
0.196^{\star} \\
-0.039^{\star} \\
0.006 \\
0.012\end{array}$ & $\begin{array}{r}-0.005^{\star} \\
0.025^{\star} \\
0.009^{\star} \\
0.004^{*} \\
0.000 \\
-0.001 \\
-0.017 \\
-0.033^{\star} \\
-0.012 \\
0.044^{\star} \\
-0.084^{*} \\
0.150^{\star} \\
0.071^{*} \\
0.141^{\star} \\
0.109^{\star} \\
-0.147^{\star} \\
0.080^{\star}\end{array}$ & $\begin{array}{c}-0.422^{\star} \\
0.007 \\
0.404^{\star} \\
-0.210^{\star} \\
-0.079 \\
0.172 \\
-0.039^{\star} \\
-0.092^{\star} \\
0.032^{\star} \\
0.003 \\
-0.084^{\star} \\
0.148^{\star} \\
0.125^{\star} \\
0.078^{\star} \\
0.105^{\star} \\
0.068^{\star} \\
0.107^{\star}\end{array}$ & $\begin{array}{c}-0.018^{\star} \\
0.013 \\
0.031^{\star} \\
0.000 \\
-0.002 \\
0.004 \\
-0.004^{\star} \\
-0.083^{\star} \\
0.003 \\
0.060^{\star} \\
-0.145^{\star} \\
0.182^{\star} \\
0.114^{\star} \\
0.186^{\star} \\
0.121^{\star} \\
-0.075^{\star} \\
0.094^{\star}\end{array}$ & $\begin{array}{l}-32^{\star} \\
-16 \\
123^{\star} \\
-17.6 \\
-8.77 \\
20.1^{\star} \\
-0.022^{\star} \\
-0.063^{\star} \\
0.037^{\star} \\
0.068^{\star} \\
0.208^{\star} \\
0.268^{\star} \\
0.373^{\star} \\
0.369^{\star} \\
0.217^{\star} \\
0.235^{\star} \\
0.281^{\star}\end{array}$ \\
\hline \multirow{3}{*}{ Folate $\left(\mu \mathrm{g} \mathrm{day}^{-1}\right)$} & \multicolumn{4}{|c|}{ Fatty acid exposures in plasma (\%) } & & & \\
\hline & \multicolumn{2}{|c|}{ Plasma cholesteryl esters } & \multicolumn{2}{|c|}{ Plasma phospholipids } & & & \\
\hline & $3 \mathrm{H}$ & $3 \mathrm{H} / 6 \mathrm{H}$ & $3 \mathrm{H}$ & $3 \mathrm{H} / 6 \mathrm{H}$ & & & \\
\hline Mean (SD) & $1.009(0.395)$ & $0.112(0.047)$ & $3.444(1.053)$ & $0.222(0.082)$ & & & \\
\hline 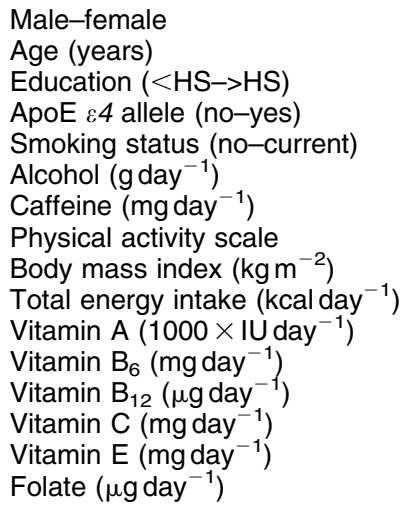 & $\begin{array}{c}-0.039^{*} \\
0.034 \\
-0.064 \\
0.005 \\
0.113^{\star} \\
0.025 \\
-0.078^{*} \\
0.002 \\
0.002 \\
-0.031 \\
0.098^{*} \\
0.094^{*} \\
0.114^{*} \\
0.052^{*} \\
0.034 \\
0.098^{*}\end{array}$ & $\begin{array}{c}-0.011 \\
0.040^{\star} \\
-0.007 \\
0.002 \\
0.009^{\star} \\
0.005 \\
-0.065^{\star} \\
0.036 \\
-0.036 \\
-0.014 \\
0.107^{\star} \\
0.091^{*} \\
0.089^{\star} \\
0.064^{\star} \\
0.044^{\star} \\
0.105^{\star}\end{array}$ & $\begin{array}{c}-0.154^{\star} \\
0.034 \\
-0.184^{\star} \\
0.009 \\
0.430^{\star} \\
-0.065^{\star} \\
-0.117^{\star} \\
0.012 \\
-0.044^{\star} \\
-0.034 \\
0.129^{\star} \\
0.119^{\star} \\
0.100^{\star} \\
0.074^{\star} \\
0.056^{\star} \\
0.111^{\star}\end{array}$ & $\begin{array}{c}-0.007^{\star} \\
0.040^{\star} \\
-0.015^{\star} \\
0.001^{\circ} \\
0.025^{\star} \\
-0.071^{*} \\
-0.093^{*} \\
0.045^{\star} \\
-0.091^{*} \\
-0.028 \\
0.131^{*} \\
0.108^{*} \\
0.077^{\star} \\
0.076^{\star} \\
0.062^{*} \\
0.111^{*}\end{array}$ & & & \\
\hline
\end{tabular}

ARIC - Atherosclerosis Risk in Communities study; SD - standard deviation; HS - high school; ApoE - apolipoprotein E; fatty acid exposure categories defined under 'Exposure assessment' in Data and methods section.

${ }^{*} P<0.05$ for hypothesis test of no difference between categories (in categorical covariates) and Pearson correlation coefficient $r=0$ for continuous covariates. 